e-ISSN. 2685-7650

Vol. 1 No. 2 (2019), pp 76-81

DOI: https://doi.org/10.33366/jkn.v1i2.23

\title{
Pesan Moral dalam Film Yowis Ben
}

\author{
Galuh Andy Wicaksono', Fathul Qorib² \\ ${ }^{1,2}$ Program Studi Ilmu Komunikasi, Universitas Tribhuwana Tunggadewi \\ Email: fathul.indonesia@gmail.com
}

\begin{abstract}
The number of movies made in Indonesia there are several films that give a good moral message in it. Through the movie "Yowis Ben" the director tried to make something new and different from the comedy genre films on previous comedy films. The purpose of this research is to know and understand the moral messages contained in the movie Yowis Ben. In this study used qualitative research method by using the research object of the Film Yowes Ben. While the data analysis technique uses the semiotic analysis of Charles Sander Pierce which is based on logic, with reasoning through the signs. The Model that shows the three main elements of the marking forming is representament, object and Interpretant. The results of this research show that the YOWIS BEN film has a moral message in various sides of life through signs that are munncul both visual and verbal in their respective stories. There is a moral message related to Bayu's life. It can therefore be concluded that the figures and the talks that exist in each scene are a representation of the moral message.
\end{abstract}

Keywords: Moral message, movie, Yowes Ben

\begin{abstract}
Abstrak: Banyaknya film yang dibuat di Indonesia terdapat beberapa film yang memberikan pesan moral yang bagus di dalamnya. Melalui film "Yowis Ben" sutradara mencoba membuat sesuatu yang baru dan berbeda dari film genre komedi pada film-film komedi sebelumnya. Tujuan penelitian ini adalah untuk mengetahui dan memahami pesan moral yang terkandung dalam film Yowis Ben.Dalam penelitian ini digunakan metode penelitian kualitatif dengan menggunakna objek penelitian yakni Film Yowes Ben. Sementara teknik analisis data menggunakan analisis semiotika Charles Sander Pierce yang didasarkan pada logika, dengan penalaran melalui tanda-tanda. Model yang memperlihatkan tiga elemen utama pembentuk tanda ialah representamen, objek dan interpretan. Hasil dari penelitian ini menunjukkan bahwa film YOWIS BEN ini memiliki pesan moral dalam berbagai sisi kehidupan melalui tanda-tanda yang munncul baik visual maupun verbal di dalam masingmasing ceritanya. Disanalah pesan moral terkait kehidupan Bayu tertuang. Dengan demikian dapat disimpulkan bahwa tokoh dan pembicaraan yang ada disetiap scene ini merupakan representasi dari pesan moral.
\end{abstract}

Kata Kunci: Pesan Moral, Film, Yowes Ben

\section{Pendahuluan}

Perkembangan teknologi komunikasi memudahkan masyarakat dalam mengakses informasi dengan cepat sehingga dapat menghubungkan masyarakat dari berbagai daerah. Salah satu bentuk kegiatan komunikasi yang memiliki kemampuan penyebaran yang luar adalah komunikasi massa. Menurut Romli (2017:1) komunikasi massa merupakan jenis penyampaian pesan (informasi atau gagasan) kepada orang banyak (publik) melalui media sehingga pesan yang sama dapat diterima secara sesaat dan bersamaan (Purwanto, 2007).

Komunikasi massa pada prakteknya bisa dilakukan menggunakan berbagai macam cara, seperti koran cetak, televisi, radio, juga film. Secara singkat film bisa dikatakan sebagai alat komunikasi massa yang berguna menyebarkan suatu gagasan ke sebagian besar orang (Suryani, 2014). Sebagai media massa, film juga membawa pesan yang hendak disampaikan kepada khalayak. Sehubungan dengan banyaknya simbol dan tanda dalam film, maka yang menjadi perhatian penelitian film pada umumnya adalah kajian semiotika (Suriadi, 2017).

Film memiliki keistimewaan karena nilai artistiknya dipadukan dengan efek gerak, suara/musik, dan serta editing komputer sehingga menimbulkan daya imajinasi yang tinggi. Alkhajar, 


\section{Jurnal Komunikasi Nusantara}

e-ISSN. 2685-7650

Vol. 1 No. 2 (2019), pp 76-81

DOI: https://doi.org/10.33366/jkn.v1i2.23

Yudiiningrum, dan Sofyan (2013) menyebut film mampu membuat kejutan dan ketakjuban. Riwu \& Pujiati (2018) menganggap film sebagai sarana baru untuk menyebarkan hiburan yang sebenarnya sudah ada di Indonesia sejak lama. Sehingga film sebenarnya hanyalah alat untuk menyebarkan gagasan.

Karena itu film banyak diproduksi karena jumlah penonton film juga terus meningakat. Pesatnya perkembangan film yang dibuat di Indonesia juga menunjukkan bahwa film sedang digemari, termasuk dengan banyaknya film komedi seperti "Warkop DKI Gengsi Dong" tahun 1980 yang disutradarai oleh Nawi Ismail, "Punk in Love" tahun 2009 yang di sutradarai oleh Ody C. Harahap, "Generasi Kocak: 90an vs Komika" tahun 2017 yang di sutradarai oleh Wishnu Kuncoro dan lain-lain.

Kebanyakan film bergenre komedi di Indonesia kurang memperhatikan pesan moral dalam sebuah film, dan hampir seluruh film bergenre komedi yang tayang di bioskop Indonesia menggunakan bahasa Indonesia. Namun di awal tahun 2018 ini perfilman Indonesia dihebohkan dengan munculnya sebuah film bergenre komedi dengan bahasa menggunakan bahasa daerah yang berjudul "Yowis Ben" yang diliris pada 22 Februari 2018 di sutradarai oleh Fajar Nugros dan codirector Bayu Skak meramaikan pasar drama komedi di layar lebar Indonesia.

Melalui film "Yowis Ben" sutradara mencoba membuat sesuatu yang baru dan berbeda dari film gensre komedi pada film-film komedi sebelumnya. Film Yowis Ben memberikan hiburan kepada penonton dengan gaya komedi yang sederhana dengan umpatan-umpatan khas menggunakan bahasa kota Malang, walaupun sederhana namun dapat menghibur penonton. Kebudayaan Malang yang ditunjukan dari perilaku aktor dalam film ini juga memberikan daya tarik untuk ditonton. Ditambah dengan banyaknya makna-makna yang tersembunyi, adegan-adegan yang memiliki simbol yang dapat dianalisis secara semiotik.

Dalam waktu dua minggu semenjak dirilis pada tanggal 28 Februari 2018 di bioskop, film Yowis Ben mendapatkan 400.000 penonton. Bayu Skak menargetkan jumlah penonton mencapai 500.000 penonton, namun kenyataanya Film Yowis Ben dalam waktu dua bulan semenjak dirilis mampu menarik penonton kurang lebih sampai 900.000 penonton (Diananto, 2018). Film Yowis Ben mendapatkan Rating 9.7/10 di situs IMDB yang mampu mengalahkan rating film Dilan. Bahkan Presiden Joko Widodo menyempatkan diri untuk menonton film "Yowis Ben" di sela kunjungan kerjanya di kota Malang. Presiden Joko Widodo juga memberikan apresiasi terhadap film tersebut, beliau mengatakan bahwa film ini cocok untuk ditonton oleh setiap generasi muda.

Sebuah komedi yang disajikan dengan teknik sinematografi dan color grading yang bagus. Dari uraian di atas, maka penulis tertarik untuk melakukan penelitian film tersebut menggunakan teori semiotika Charles Sanders Pierce (Jusiano \& Dewi, 2018). Pierce dipilih karena teori Pierce merupakan grand teori dalam ilmu semiotika yang sering digunakan dalam penelitian selain Ferdinand De Saussure.

\section{Metode Penelitian}

Penelitian ini menggunakan metode penelitian kualitatif karena dalam pelaksanaannya meliputi data analisis dan interpretasi tentang arti dan data yang diperoleh. Objek penelitian ini adalah Film Yowis Ben, adapun unit analisis penelitiannya adalah potongan-potongan gambar atau visual baik secara artistik maupun act pada beberapa tokoh, serta adegan-adegan yang terdapat pada film "Yowis Ben", dan juga dari dialog-dialog yang ada pada film yang berkaitan dengan rumusan masalah tersebut. 


\section{Jurnal Komunikasi Nusantara}

e-ISSN. 2685-7650

Vol. 1 No. 2 (2019), pp 76-81

DOI: https://doi.org/10.33366/jkn.v1i2.23

Data primer dan data sekunder yang sudah terkumpul dibaca dan diamati atau observasi. Setelah memperoleh gambaran yang bersifat umum dan mencangkup yang dipermasalahkan peneliti mungumpulkan scene-scene yang berkaitan dengan pesan moral dan melibatkan beberapa tokoh. Setelah terkumpul beberapa scene, peneliti membaginya dalam beberapa shot untuk memudahkan pemaknaan secara representamen dan interpretan.

Menurut Sobur (2009:148), langkah- langkah yang dilakukan dalam menganalisa data adalah dengan menentukan korpus yang berupafoto dari Film Yowis Ben. Kemudian dianalisis menggunakan analisis teori Semiotika Charles Sander Peirce, semiotika didasarkan pada logika, karena logika mempelajari bagaimana orang bernalar, sedangkan penalaran menurut Peirce dilakukan melalui tanda-tanda. Charles Sanders Pierce membuat model dalam menganalisa makna dari tandatanda atau yang sering disebut dengan triadic (segitiga makna/triangle meaning). Model yang memperlihatkan tiga elemen utama pembentuk tanda, yaitu: Representamen (sesuatu yang mempresentasikan sesuatu yang lain, Objek (sesuatu yang dipresentasikan atau digambarkan) dan Interpretant (interpretasi seseorang tentang tanda) (Piliang, 2003:267).

\section{Hasil dan Pembahasan}

Objek pada penelitian ini dipilih 17 scene yang akan dijabarkan berdasarkan makna Representamen, object, interpretan. Objek merupakan sesuatu yang dirujuk, atau sesuatu yang objektif yang bentuk dan keadaannya sama dilihat oleh semua orang (Philiph: 2018). Pesan moral yang terkandung dalam masing-masing scene. Penjabaran kategori tersebut berdasarkan visual (gambar) dan verbal (dialog) yang terdapat dalam scene tersebut. Sementara untuk pemilihan scene, di ambil berdasarkan latar belakang yang diusung dalam film dan kemudian di deskripsikan sesuai dengan teori semiotika Charles S Pierce yang juga terkenal dengan konsep Triadik atau Trikolotomi yang terdiri dari tiga unsur tanda.

\section{Rerendah Hati}

a. Berdasarkan representamen, tanda terbagi menjadi beberapa bagian seperti qualisign, sinsign, dan legisign. Qualisign dalam scene ini adalah meskipun Bayu di hina oleh Roy karena sikapnya yang katrok, tapi ia tetap rendah hati. Sementara untuk sinsignya Roy berusaha mengejek penampilan bayu. Sedangkan untuk legisignnya adalah respon bayu yang tetap berusaha mempertahankan prinsipnya di hadapan Roy menunjukkan bahwa hal itu berhubungan dengan rendah hati.

b. Berdasarkan Objek, tanda terbagi menjadi ikon, indeks, dan simbol. Ikon dalam scene ini ditunjukkan dengan baju bayu yang berbeda dengan baju Susan dan Roy. Sementara indeks dalam scene ini ditunjukkan dengan tudingan tangan Roy ke arah Bayu serta muka Roy yang mengejek Bayu. Kedua tanda ini mengindekskan bahwa Roy benar-benar merendahkan Bayu di hadapan Susan dan mencoba membandingkan Bayu dengan Roy agar Susan dapat melihatnya. Selanjutnya jika dihubungkan dengan dialog yang disampaikan, ucapan Roy mengindekskan perasaan benci dan kesal kepada Bayu tetapi Bayu menjawab apa adanya. Objek ketiga yakni simbol ditunjukkan dengan ekspresi Bayu yang tetap merasa sudah berkata apa adanya dan hal tersebut menyimpulkan bahwa Bayu telah merendahkan hati di hadapan Roy dan Susan.

c. Berdasarkan interprtant, tanda terbagi menjadi rheme, dicent, dan argument. Dari scene di atas, rheme berada pada baju Bayu yang berbeda. Sedangkan Dicent-nya berada pada point dimana Roy menunjuk sinis kepada Bayu dan mengejeknya. Sedangkan argument menunjukkan bahwa reaksi Bayu yang apa adanya menggambarkan bahwa ia rendah hati. 


\section{Jurnal Komunikasi Nusantara}

e-ISSN. 2685-7650

Vol. 1 No. 2 (2019), pp 76-81

DOI: https://doi.org/10.33366/jkn.v1i2.23

\section{Toleransi Beragama}

a. Berdasarkan representamen, tanda terbagi menjadi beberapa bagian seperti qualisign, sinsign, dan legisign. Qualisign dalam scene ini adalah meskipun Ayah Nando dan Nando beragama beda, mereka memiliki tempat yang bagus dan cocok untuk melaksanakan sholat. Sehingga, Iyan dapat melaksanakan sholat secepatnya. Sementara untuk sinsignya Ayah Nando mendukung kegiatan Iyan. Sedangkan legisignnya adalah ucapan Ayah Nando yang mengatakan bahwa Iyan tidak perlu khawatir untuk melakukan sholat menjadi tanda bahwa ayah Nando memiliki toleransi dalam beragama.

b. Berdasarkan Objek, tanda terbagi menjadi ikon, indeks, dan simbol. Ikon dalam scene ini ditunjukkan dengan ucapan ayah nando yang akan mengantar Iyan sholat. Sementara indeks ditunjukkan dengan kalimat bahwa di rumah Nando terdapat tempat yang biasa digunakan karyawan untuk melakukan ibadah. Sementara untuk objek simbol ditunjukkan dengan senyuman Nando dan Bayu yang juga turut senang mendengar ucapan ayah nando.

c. Berdasarkan Interpretantdari scene tersebut, rheme berada pada dialog seluruh tokoh yang ada dalam scene. Sedangkan dicent-nya berada pada point dimana Ayah Nando menenangkan Iyan agar ia dapat tenang melakukan sholat. Sedangkan argumentnya menunjukkan bahwa seluruh scene menggambarkan toleransi beragama.

\section{Kasih Sayang}

a. Berdasarkan representamen dalam scene di atas, tanda qualisign berada pada bagian dimana Cak Jon memberikan nasehat kepada Bayu dan menyemangati Bayu yang telah gagal melakukan pertunjukannya yang pertama di panggung. Sementara sinsign ada pada dialog Bayu yang terus menjawab dialog Cak Jon dengan emosi tetapi Cak Jon menanggapinya dengan tenang. Sedangkan legisignnya berada pada saat Cak Jon menenangkan Bayu yang telah gagal.

b. Berdasarkan objek dalam scene ini ditandai dengan ikon Cak Jon yang tenang menanggapi emosi Bayu yang gagal manggung. Sementara indeks ditunjukkan dengan emosi Bayu yang meluap saat melihat Cak Jon. Kejadian di scene sebelumnya membuat Bayu emosi. Tetapi sikap Cak Jon yang tenang berusaha memberikan Bayu nasehat. Tanda Objek simbol ditunjukkan dengan perkataan Cak Jon tentang kegagalan.

c. Berdasarkan interpretant, tanda rheme ucapan Cak Jon kepada Bayu tentang kegagalan. Sedang dicent-nya adalah ekspresi Bayu yang marah dengan kegagalannya. Kemudian argument ditunjukkan dari ucapan Cak Jon yang menasehati Bayu. Hal ini juga memberikan nilai sebagai simbol bahwa Cak Jon sangat sayang dengan Bayu.

\section{Kerja Keras}

a. Berdasarkan representamen, qualisigndalamsceneini ditandai dengan pemberian piala dan ucapan selamat dari juri kepada Bayu. Sementara sinsignnya berada pada saat juri menepuk pundak Bayu seperti menyimbolkan rasa bangga dan haru. Sedangkan untuk legisignnya berada pada saat Bayu tersenyum melihat piala yang didapatkan dan ucapan luar biasa yang diterimanya dari juri.

b. Berdasarkan objek dalam scene ini ikon ditandai dengan piala yang diterima Bayu di atas panggung. Sementara indeks ditunjukkan dengan suasana disekitar Bayu yang bising dan senang ketika Bayu menerima piala. Sedangkan untuk simbol ditandai ketika Bayu memengang piala dan Nando yang memegang piagam penghargaan serta didukung dengan sikap juri yang memberikan selamat kepada mereka. 


\section{Jurnal Komunikasi Nusantara}

e-ISSN. 2685-7650

Vol. 1 No. 2 (2019), pp 76-81

DOI: https://doi.org/10.33366/jkn.v1i2.23

c. Berdasarkan interpretan dalam scene ini pada tanda rheme ditunjukkan dari piala dan sertifikat yang diterima. Sedangkan dicent-nya berada pada respon juri saat menepuk pundak Bayu dan memberikan selamat. Sedangkan argument menunjukkan bahwa keberhasilan Bayu dan teman-temannya berdiri di panggung itu dan menerima hadiah dari juri merupakan hasil kerja keras dari Bayu dan teman-temannya selama ini.

\section{Kemandirian}

a. Berdasarkan representamen, tanda qualisign berada pada scene ketika Bayu dengan bangga membawa tas berisi pecel ke sekolah. Sinsign berada pada dialog yang diucapkan teman Bayu yang memanggilnya dengan sebutan Pecel Boy. Sementara legisignnya berada pada dialog Bayu yang tetap merasa senang mendapatkan panggilan itu agar barang dagannya cepat laku.

b. Berdasarkan objek ikon dalam scene diatas berada pada tas berisi pecel yang dibawa oleh Bayu ke sekolah. Sementara indeks dalam scene berada pada dialog teman bayu. Sedangkan objek simbol ditunjukkan dengan reaksi Bayu yang tetap menerima sebutan yang disematkan temannya kepadanya.

c. Berdasarkan interpretant, tanda rheme ditunjukkan pada tas belanja Bayu. Sedangkan dicent berada pada scene ketika Bayu mendengar temannya memanggilnya Pecel Boy. Sementara argument menunjukkan bahwa Bayu merasa lapang dengan ejekan tersebut karena selama ini Ia telah merasa membantu ibunya berjualan. Hal ini juga menyimpulkan bahwa Bayu memiliki jiwa kemandirian yang tinggi.

\section{Persahabatan}

a. Berdasarkan representamen dalam scene di atas, tanda qualisign berada pada dialog seluruh tokoh yang berusaha memecahkan masalah yang mereka lalui bersama. Sementara sinsign ada pada dialog Bayu saat membicarakan tentang cara menjadi populer. Sedangkan legisignnya berada pada adegan saat Doni ikut berfikir dengan topik yang mereka bicarakan.

b. Berdasarkan objek dalam scene ini ditandai dengan ikon dialog mereka yang sama-sama tegang dan serius memikirkan cara menjadi populer bersama selain ngeband. Indeks ditunjukkan dengan ekspresi menggebu-gebu Bayu yang berbagi pemikiran tentang masalah yang mereka hadapi. Sedangkan objek simbol ditunjukkan dengan ekspresi yang lainnya yang ikut mendengarkan dengan serius.

c. Berdasarkan interpretant, tanda rheme ada pada ekspresi seluruh tokoh yang serius mendengarkan percakapan. Sedangkan dicent-nya berada pada Dialog Bayu dan Doni yang saling membicarakan masalah dan meminta solusi. Sementara argument menunjukkan bahwa mereka semua berusaha memecahkan masalah bersama-sama.

\section{Pendidikan}

a. Berdasarkan representamen dalam scene di atas, tanda qualisign berada pada bagian dimana Pak Satpam marah melihat ada sebuah motor yang tidak terparkir dengan baik di tempatnya. Sementara sinsignya ada pada saat Pak Satpam tersebut meminggirkan motor ke tempat yang sebenarnya. Sedangkan legisignnya berada pada dialog Pak Satpam yang menyumpahi pemilik motor tentang perbuatannya.

b. Berdasarkan objek dalam scene ini ditandai dengan ikon Baju Satpam dan sebuah motor yang tidak terparkir ditempatnya. Sementara indeks ditunjukkan dengan emosi pak satpam yang mencari-cari pemilik motor sambil menyumpahi pemilik motor itu. Sedangkan objek simbol ditunjukkan dengan pak satpam membawa motor tersebut ke tempat yang seharusnya.

c. Berdasarkan interpretant, tanda rheme ada pada atribut seragam pak satpam. Sedangkan dicent-nya berada pada kemarahan pak satpam sambil membawa motor ke tempat parkir. 


\section{Jurnal Komunikasi Nusantara}

e-ISSN. 2685-7650

Vol. 1 No. 2 (2019), pp 76-81

DOI: https://doi.org/10.33366/jkn.v1i2.23

Sementara argument menunjukkan bahwa pa satpam marah karena pemilik motor yang ternyata adalah Bayu tidak mentaati tata tertib di sekolah dengan tidak memarkir motor di tempat parkir.

\section{Kesimpulan}

Berdasarkan analisis yang dilakukan peneliti menyimpulkan bahwa, film YOWIS BEN ini memiliki pesan moral dalam berbagai sisi kehidupan melalui tanda-tanda yang muncul baik visual maupun verbal di dalam masing-masing ceritanya. Tokoh yang sering muncul dalam film ini adalah Bayu dan rekan bandnya. Walaupun bergenre komedi, film YOWIS BEN ini juga selalu menampilkan sisi baik atau prilaku yang bermoral yang patut dicontohi oleh para penggemar film tersebut, penokohan yang ada dalam film ini mewakili lapisan masyarakat. Khususnya masyarakat menengah kebawah. Dan setting cerita dalam film ini menggambarkan kehidupan Bayu yang penuh dengan perjuangannya hingga akhirnya ia suskses. Sedangkan tanda-tanda verbal yang muncul dalam film YOWIS BEN ini, muncul disetiap pembicaraan dan perbuatan yang ditunjukan oleh para tokoh. Disanalah pesan moral terkait kehidupan Bayu tertuang. Dengan demikian dapat disimpulkan bahwa tokoh dan pembicaraan yang ada disetiap scene ini merupakan representasidari pesan moral.

\section{Daftar Pustaka}

Alkhajar, E.N., Yudiningrum, F.R. \& Sofyan, A. (2013). Film sebagai Propaganda di Indonesia. Jurnal Forum Ilmu Sosial, 40 (2), 189-200.

Piliang, Y. A. (2003). Hipersemiotika Tafsir Cultural Studie Atas Matinya Makna. Yogyakarta: Jalasutra.

Diananto, W. (2018). Yowis Ben Kalahkan Dilan 1990, Bayu Skak: Ini di Luar Ekspektasi. Tabloidbintang.com

Jusiano, P. \& Dewi, S. I. (2018). Analisis Semiotika Ketidakadilan Gender Terhadap Perempuan Dalam Film Marlina Si Pembunuh Empat Babak. Jurnal JISIP, 7 (2) 136-147.

Purwanto, N. (2007). Psikologi Pendidikan Remaja. Bandung: Rosdakarya.

Riwu, A \& Pujiati, T. (2018). Analisis Semiotika Rolant Barthes pada Film 3 Dara. Jurnal Deiksis, 10 (3) $212-223$.

Suryani, Ita. (2014). Peran Media Film sebagai Media Kampanye Lingkungan Hidup. Jurnal Ilmu Komunikasi Avant Garde, 2 (2), 79-90.

Romli, K. (2017). Komunikasi Massa. Jakarta: Gramedia Widiasarana.

Sobur, A. (2016). Semiotika Komunikasi. Bandung: PT Remaja Rosdakarya.

Suriadi \& Dewi, S. I. (2017). Analisis Semiotik Pesan Perjuangan Pada Film 3 Srikandi Karya Iman Brotoseno. Jurnal JISIP, 6 (3) 1-5. 